\title{
Francisella tularensis'in Moleküler Tanısında Yeni Geliştirilen Kullanıma Hazır Ticari PCR Kitinin Etkinliğinin Değerlendirilmesi
}

\section{Evaluation of a Newly-Developed Ready-to-Use Commercial PCR kit for the Molecular Diagnosis of Francisella tularensis}

\author{
Bekir ÇELEBi ${ }^{1}$, Selçuk KILIÇ${ }^{1}$, Murat YEŞiLYURT² ${ }^{2}$ Bülent ACAR ${ }^{1}$ \\ ${ }^{1}$ Türkiye Halk Sağlığı Kurumu, Ulusal Tularemi Referans Laboratuvarı, Ankara. \\ ${ }^{1}$ Public Health Institution of Turkey, National Tularemia Reference Laboratory, Ankara, Turkey. \\ ${ }^{2}$ Tekirdağ Devlet Hastanesi, Enfeksiyon Hastalıkları Kliniği, Tekirdağ. \\ 2 Tekirdag State Hospital, Infectious Diseases Clinic, Tekirdag, Turkey.
}

Geliş Tarihi (Received): 31.08.2013 • Kabul Ediliş Tarihi (Accepted): 22.11.2013

\section{ÖZET}

Tularemi, nadir görülen bir zoonoz olmasına karşın, biyolojik silah olarak değerlendirilmesi ve son yıllarda ortaya çıkan salgınlar nedeniyle yeniden önem kazanan bir enfeksiyon olmuştur. Tulareminin laboratuvar tanısı, uygun epidemiyolojik verilerin varlığında semptomların başlangıcından sonra 1-2 hafta arayla alınan serum örneklerinde etkene karşı gelişen antikorların gösterilmesiyle konulmaktadır. Ancak bu yöntem, semptomların yeni başladığı hastalığın erken döneminde ve biyolojik harp ajanların kasıtlı salınması durumlarında, hızlı tanı açısından sınırlı kullanıma sahiptir. Kültür ve serolojideki sınırlamalar yeni tanı tekniklerinin gündeme gelmesine yol açmıştır. Tulareminin hızı tanısına yönelik olarak, çeşitli konvansiyonel ve gerçek zamanlı polimeraz zincir reaksiyonu (rtPCR) yöntemleri geliştirilmiştir. Ancak PCR yöntemlerinin, tularemi gibi hastalığın endemik olarak görüldüğü yeterli altyapısı olmayan kırsal bölgelerdeki merkezlerde uygulanabilmesi zordur. Ülkemizde biyolojik harp maddelerinin tanısına yönelik olarak sahada kullanılmak amacıyla konvansiyonel PCR için gerekli tüm cihaz, ekipman ve bileşenlerini [DNA4U ${ }^{\circledR}$ Bakteri Genomik DNA İzolasyon Kiti, CubeCycler ${ }^{\circledR}$ (Kişisel ısı döngü cihazı), PCR4U ${ }^{\circledR}$ Biyoterörizm Ajanlar Tespit Kiti, elektroforez tankı, güç kaynağı, agaroz jel elektroforez tamponu] içeren bir "Araç Kutusu (Toolbox)" geliştirilmiştir. Bu çalışmada, tularemi tanısında tul4 genini hedefleyen kullanıma hazır F.tularensis PCR kitinin (Nanobiz, Ankara, Türkiye) etkinliğinin araştırılması ve sonuçların "in-house" konvansiyonel ve rtPCR testi ile karşılaştırılması amaçlanmıştır. Bu amaçla, dört Francisella spp. standart suşunun genomik DNA'sı, 15 Francisella spp. saha (insan, hayvan, su) izolatı, filogenetik olarak F.tularensis ile ilişkili 13 bakteri türüyle tularemi ön tanılı 60 olgudan alınan lenf nodu aspirat örnekleri çalışmaya alınmıştır. "In-house" PCR yöntemi ile karşılaştırıldığında Nanobiz PCR kitinin duyar-

Iletişim (Correspondence): Iletişim (Correspondence): Doç. Dr. Selçuk Kılıç, Türkiye Halk Sağlığı Kurumu, Ulusal Yüksek Riskli Patojenler Referans Laboratuvarı, Adnan Saygun Cad. No: 55, F Blok 06100 Sihhiye, Ankara, Türkiye. Tel (Phone): +90 312565 5435, E-posta (E-mail): mdskilic2003@yahoo.com 
lılık, özgüllük, pozitif ve negatif prediktif değerleri \%100 olarak bulunmuş; en düşük saptama sınırı her bir reaksiyon tüpü için 100 genomik ekivalan olarak saptanmıştır. PCR için gerekli tüm kimyasallar, cihaz ve ekipmanları içeren kullanıma hazır PCR tanı sistemi laboratuvarlarda uygulanacak olan konvansiyonel PCR'ye göre hızlı ve doğru bir alternatiftir. Sonuç olarak, kullanıma hazır PCR kiti sınırlı kaynakların söz konusu olduğu uzak bölgeleri etkileyen tularemi salgınlarında F.tularensis tanısı için değerli bir tanı aracı olarak değerlendirilmiştir.

Anahtar sözcükler: Tularemi; Francisella tularensis; hızlı tanı; PCR; Türkiye.

\begin{abstract}
Tularemia is a rare zoonotic infection, however, considerations of tularemia as a biological weapon and several recent major epidemics have caused renewed interest in this disease. Laboratory diagnosis of tularemia is done in the presence of appropriate epidemiological data, by the demonstration of specific antibodies in the serum samples obtained with 1-2 week intervals following the development of symptoms. It is an a posteriori analysis with limited use for prompt diagnosis of the patient during the early symptomatic phase and deliberate release of biological agents. Limitations in both culture and serology have led to substantial research in the development of new diagnostic techniques. Several PCR methods for tularemia have been developed, both for conventional and real-time polymerase chain reaction (rtPCR). However, PCR methods are hard to be deployed in remote endemic areas that lack sufficient infrastructure. Recently a "Toolbox" which includes all instruments, equipments and solutions [DNA4U ${ }^{\circledR}$ Bacteria Genomic DNA Isolation Kit, CubeCycler ${ }^{\circledR}$ (Personal Thermal Cycler), PCR4U ${ }^{\circledR}$ Bioterrorism Agents Detection Kit, electrophoresis tank, power supply, ready-agarose gel and electrophoresis buffer] necessary for conventional PCR, was developed for the identification of bioterrorism agents in the field. In this study we aimed to evaluate the efficacy of a ready-to-use commercial PCR kit (Nanobiz, Ankara, Turkey) targeting the tul4 gene, for the diagnosis of tularemia and to compare the results with an in-house conventional PCR and a rtPCR test. We applied the assay to a collection of four F.tularensis standard strains, 15 field isolates (from humans, animals, water), 13 non-Francisella strains which are phylogenetically related to F.tularensis and a total of 60 lymph node aspirates obtained from suspected tularemia cases. Compared to the in-house PCR method used in our laboratory, the sensitivity, specificity, positive and negative predictive values of Nanobiz PCR Toolbox assay were found to be $100 \%$. The lowest detection limit of this method was determined as 100 genomic equivalent per PCR reaction mix. The new PCR kit is a rapid and accurate alternative to the conventional PCR methods since the toolbox includes all of the required chemicals, accessories and equipments. This ready-to-use PCR assay was appraised to be a valuable diagnostic tool for the detection of F.tularensis in the outbreak settings particularly in remote areas with limited resources.
\end{abstract}

Key words: Tularemia; Francisella tularensis; rapid diagnosis; PCR; Turkey.

\title{
Giriş
}

Tularemi, Francisella tularensis'in etken olduğu kuzey yarım kürede dağııım gösteren

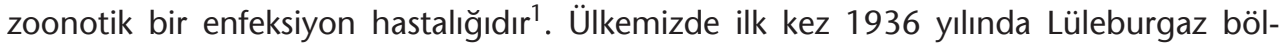
gesinde tanımlanan tularemi, yakın zamana kadar özellikle Marmara ve Batı Karadeniz Bölgesinde küçük salgınlar şeklinde görülürken, 2004 yılından sonra diğer bölgelerde de salgınlara neden olması nedeniyle 2005 yılında bildirimi zorunlu hastalıklar listesine alınmışıı ${ }^{2}$. Son yıllarda, ülkemizde tulareminin daha önceden bildirilmediği bölgelerde de salgınlara neden olması ve ülkemizin tüm coğrafi bölgelerinden bildirilen olgu sayısında 
belirgin artış görülmesi, bu enfeksiyonun önemli bir halk sağlığı sorunu haline gelmesine neden olmuştur ${ }^{3-6}$. F.tularensis, dış ortam koşullarına dayanıklı olması, enfektif dozunun düşük olması (10-50 bakteri), kolay yayılabilmesi ve oluşturduğu klinik tabloların yüksek mortalitesi nedeniyle önemli biyolojik silah ajanları arasında yer almaktadır ${ }^{7,8}$.

Tulareminin tanısı, bakteriyolojik, moleküler ve serolojik yöntemlerle konulmaktadır. Kesin tanı, klinik örneklerden etkenin izolasyonu ile yapılmakla birlikte, bakterinin özel kültür koşullarına gereksinim duyması ve biyogüvenlik düzeyi yüksek (BL-3) laboratuvarlarda çalışma zorunluluğu, kültür yönteminin kullanımını sınırlamaktadır ${ }^{9,10}$. Tanıda sıklıkla tercih edilen serolojik testler ise, antikorların genellikle hastalığın ikinci haftasına kadar saptanamaması ve serokonversiyonun gösterilmesi için zamana ihtiyaç duyulması gibi nedenlerle hızlı tanıda yeterince yararlı olmamaktadır ${ }^{1,9-12}$. Dolayısıyla moleküler yöntemler, günümüzde tulareminin hızlı tanısında ön plana geçmiştir ${ }^{11-16}$. Nükleik asit amplifikasyon testlerinin yüksek duyarlılık ve özgüllüğü, klinik ve çevresel örneklerde düşük sayıda bulunan mikroorganizmaların araştırılmasına olanak sağlamaktadır ${ }^{13,17-19}$. Bu çalışmada, ülkemizde biyolojik harp maddelerinin sahada hızlı bir şekilde tanımlanabilmesi için tüm polimeraz zincir reaksiyonu (PCR) bileşenlerini içeren bir sistemin, tularemi tanısındaki etkinliğinin değerlendirilmesi amaçlanmıştır.

\section{GEREÇ ve YÖNTEM}

Çalışmaya, Türkiye Halk Sağlığı Kurumu, Ulusal Tularemi Referans Laboratuvarında insan, hayvan ve su gibi çeşitli kaynaklardan izole edilmiş olan 15 Francisella spp. suşu, 2011-2012 yılları arasında tularemi ön tanısıyla gönderilen lenf nodu aspiratı (LNA) örneklerinden izole edilen 60 F.tularensis suşu ve dört standart Francisella spp. suşu dahil edildi (Tablo I). DNA amplifikasyonunun F.tularensis'e özgün olup olmadığını değerlendirmek amacıyla da, Francisella türlerine benzer hücre içi yaşam döngüsüne sahip olan veya filogenetik olarak F.tularensis ile ilişkili türlerden 13 bakteri suşu çalışmaya alındı (Tablo I).

Klinik örneklerden ve standart/koleksiyon suşlarından bakteri DNA'sı, ekstraksiyon kiti (DNA ${ }^{\circledR} 4$ U-Bakteri genomik DNA İzolasyon Kiti, Nanobiz, Ankara) kullanılarak elde edildi. PCR reaksiyon tüplerinde liyofilize olarak bulunan PCR karışımına (PCR4U ${ }^{\circledR}$ Bioterror Agents- F.tularensis tespit kiti) $25 \mu \mathrm{l}$ DNAz ve RNAz içermeyen steril su eklendikten sonra, birkaç kez mikrosantrifüj işlemiyle peletin tamamen erimesi sağlandı. PCR karışımına sulandırıldıktan sonra üzerine 3-5 $\mu$ l (50-100 ng DNA) DNA örneği eklendi. Amplifikasyon, "kişisel" Isı döngü cihazında (CubeCycler, Nanobiz, Ankara), $95^{\circ} \mathrm{C}$ 'de 10 dakika başlangıç denatürasyonu takiben, $94^{\circ} \mathrm{C}^{\prime}$ de 30 saniye denatürasyon, $60^{\circ} \mathrm{C}^{\prime}$ de 1 dakika bağlanma ve $72^{\circ} \mathrm{C}^{\prime}$ de 1 dakika uzamayı içeren $30 \mathrm{PCR}$ döngüsü ve $72^{\circ} \mathrm{C}^{\prime}$ de 5 dakika son uzama olacak şekilde uygulandı. PCR sonuçlarının görüntülenmesi amacıyla, amplifikasyon ürünleri $10 \mu$ l olacak şekilde, firma tarafından hazır olarak sağlanan \%1.5 agaroz jele yüklendi ve elektroforez işlemine tabi tutuldu. Sonuçlar standart moleküler ağırlık ile karşılaştırılarak değerlendirildi. 
Francisella tularensis'in Moleküler Tanısında Yeni Geliştirilen Kullanıma Hazır Ticari PCR Kitinin Etkinliğinin Değerlendirilmesi

\begin{tabular}{|c|c|c|}
\hline Suş & & PCR sonucu \\
\hline Francisella tularensis subsp. holarctica & NCTC 10857 (Live Vaccine Strain) & Pozitif \\
\hline Francisella tularensis subsp. tularensis & Schu S4 & Pozitif \\
\hline Francisella tularensis subsp. novicida & U112 & Pozitif \\
\hline Francisella philomiragia & 13404 & Negatif \\
\hline Borrelia burgdorferi & B31 (ATCC 35210) & Negatif \\
\hline Brucella abortus biovar 1 & 544 & Negatif \\
\hline Brucella melitensis biovar 1 & $16 \mathrm{M}$ & Negatif \\
\hline Escherichia coli & ATCC 25922 & Negatif \\
\hline Haemophilus influenzae Type B & ATCC 10211 & Negatif \\
\hline Legionella pneumophila & ATCC 43111 & Negatif \\
\hline Bordetella pertussis & ATCC 9797 & Negatif \\
\hline Pseudomonas aeruginosa & ATCC 27853 & Negatif \\
\hline Yersinia pestis & NCTC 2868 & Negatif \\
\hline Yersinia enterocolitica Tip 09 & RSKK 921 & Negatif \\
\hline Vibrio cholerae & NCTC 8021 & Negatif \\
\hline Burkholderia mallei & RSKK 11 (NCTC 10260) & Negatif \\
\hline Bartonella henselae & RSKK & Negatif \\
\hline
\end{tabular}

Kullanıma hazır PCR kitinin (Nanobiz ${ }^{\circledR}$ ) etkinliği, konvansiyonel tul4 ve üç farklı genomik bölgeyi (ISFtu2, 23kDa ve tul4) saptayan gerçek zamanlı PCR (rtPCR) ile karşılaştırıldı. PCR kitinin analitik duyarlılığını [Saptama sınırı; Limit of Detection (LOD)] belirlemek için $10^{6}$ genomik ekivalan (GE) içeren pozitif kontrol örneğinden $10^{1}-10^{6}$ arasında GE olacak şekilde hazırlanan örnekler üç PCR yöntemiyle çalışıldı.

\section{BULGULAR}

Çalışmamızda, çeşitli kaynaklardan izole edilen 15 Francisella spp. suşu ile üç standart F.tularensis DNA'sında özgül 420 baz çifti (bç) büyüklüğünde bant oluşumu saptanmış ve F.tularensis varlığı PCR ile de doğrulanmıştır. PCR kitinin özgüllüğünü saptamak için test edilen filogenetik olarak F.tularensis ile yakın ilişkili 13 bakterinin DNA örneklerinde herhangi bir amplifikasyon gözlenmemiştir (Şekil 1).

Tularemi şüpheli olgulara ait 60 LNA örneğinden 45'i, laboratuvarımızda kullanılan tul4'e özgül konvansiyonel PCR ve üç farklı genomik lokusu (ISFtu2, 23kDa, tul4) hedefleyen rtPCR ile pozitif olarak bulunmuştur. Kalan 15 örnek, kültür ve PCR ile negatif olarak değerlendirilmiş; ancak bu olguların tularemi mikroaglütinasyon testi pozitif olarak saptanmıştır. Nanobiz PCR kiti ve "in-house" PCR yöntemleriyle pozitif bulunan LNA örneklerinin tümünde 420 bç büyüklüğünde bant belirlenmiştir. Kültür ve PCR negatif, 


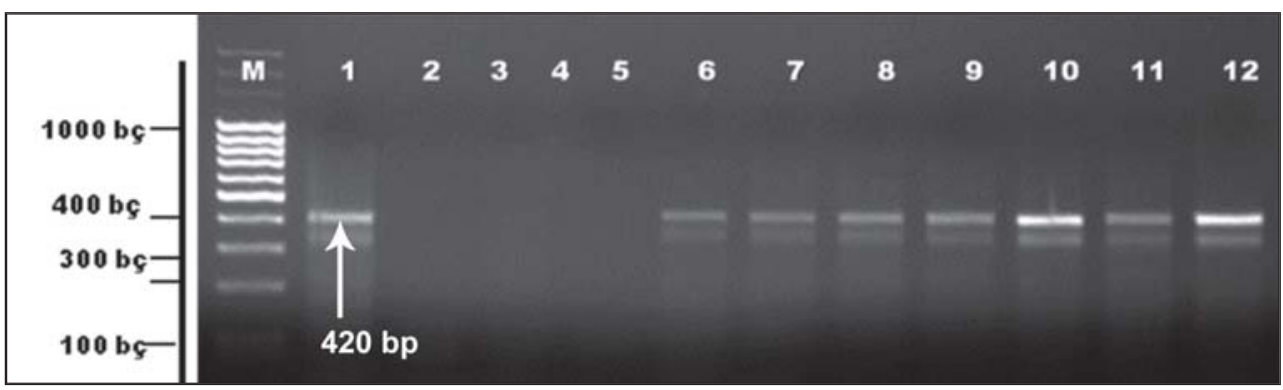

Şekil 1. Kullanıma hazır F.tularensis PCR kiti ile elde edilen sonuçlar [Hat 1: F.tularensis NCTC 10857; Hat 2: Negatif kontrol; Hat 3: Brucella melitensis ATCC 23456; Hat 4: Yersinia enterocolitica; Hat 5: Vibrio chloreae; Hat 6-9 ve 11: Klinik örnekler (Lenf aspiratı); Hat 10 ve 12: Şüpheli klinik izolatlar].

serolojik testleri pozitif olan 15 olgunun LNA örneklerinde Nanobiz kiti ile de negatif sonuç alınmıştır. Bu sonuçlara göre "in-house" PCR ile karşılaştırıldığında, Nanobiz PCR kitinin duyarlılık ve özgüllüğü \%100 olarak bulunmuş; tularemi şüpheli olgulara ait LNA örneklerinin sonuçlarına göre, pozitif ve negatif prediktif değeri de \%100 olarak değerlendirilmiştir.

PCR kitinin analitik duyarlılığını belirlemek amacıyla, seri dilüsyonları yapılan pozitif kontrol örneği ile Nanobiz ${ }^{\circledR}$ F.tularensis PCR kitinin saptama sınırı 100 GE/reaksiyon olarak bulunmuştur (Şekil 2). Konvansiyonel tul4 PCR yönteminde saptama değeri $100 \mathrm{GE}$ iken, "in-house" rtPCR ile 25 GE olarak saptanmıştır.

\section{TARTIŞMA}

Tularemide erken dönemdeki semptomlar özgül olmadığı için, tedavide gecikmeye bağlı gelişecek komplikasyonların önlenmesi amacıyla hızlı ve güvenilir laboratuvar tanı araçlarına gereksinim vardır ${ }^{1,10,11}$. Son yıllarda F.tularensis'in saptanması amacıyla PCR kullanımına yönelik birçok çalışma yayınlanmıştır ${ }^{12-16}$. Tularemi tanısında konvansiyonel ve gerçek zamanlı PCR teknikleri kullanılmakla birlikte, rtPCR, konvansiyonel PCR yöntemine göre daha yüksek duyarlılık ve özgüllüğe sahiptir ${ }^{11,17,20,21}$. Ancak bu üstünlük,

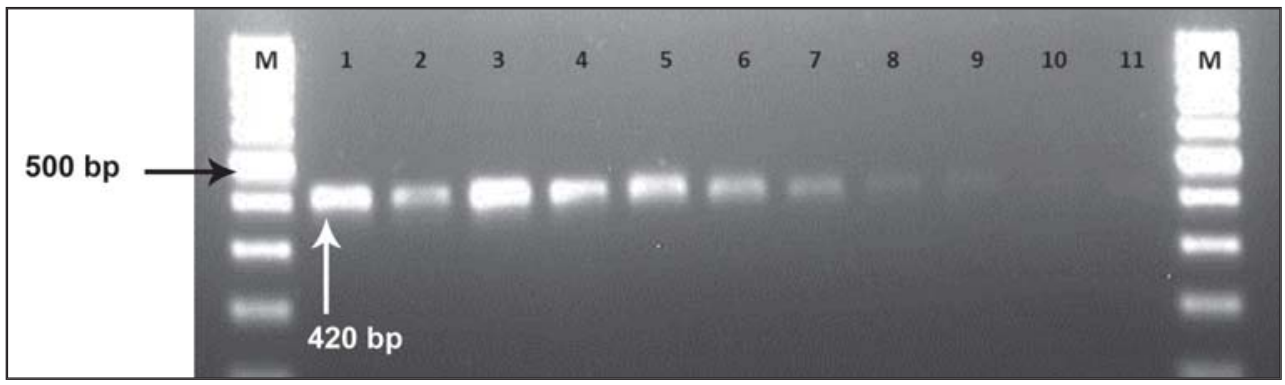

Şekil 2. Kullanıma hazır F.tularensis PCR kitinin saptama sınırı sonuçları [M: DNA belirteci; Hat 1: Pozitif kontrol F.tularensis NCTC 10857 (420 bç); Hat 2: F.tularensis $10^{6}$ GE; Hat 3: F.tularensis $10^{5}$ GE; Hat 4: F.tularensis $10^{4} \mathrm{GE}$; Hat 5: F.tularensis $10^{3} \mathrm{GE}$; Hat 6: F.tularensis $5 \times 10^{2} \mathrm{GE}$; Hat 7: F.tularensis $250 \mathrm{GE}$; Hat 8: F.tularensis $100 \mathrm{GE;} \mathrm{Hat} \mathrm{9:} \mathrm{F.tularensis} 50 \mathrm{GE;} \mathrm{Hat} \mathrm{10:} \mathrm{F.tularensis} 10 \mathrm{GE}$, Hat 11: Negatif kontrol]. 
seçilen hedef bölgelere ve kullanılan örnek türüne bağlı olarak değişiklik göstermekte$\operatorname{dir}^{11,13}$. PCR ile F.tularensis'e ait dış membran proteinlerini kodlayan tul4 ve fopA, insersiyon elementi (ISFtu2) ve makrofaj enfeksiyonunda eksprese edilen bir proteini kodlayan 23 kDa gen gibi başıca hedef bölgeler çoğaltılmaktadır ${ }^{10-13,20-22}$. F.tularensis'in tüm alt türlerinde ortak olarak bulunan 17 kDa'luk lipoproteini kodlayan tul 4 geni, tulareminin moleküler tanısında en fazla tercih edilen hedef bölgedir ${ }^{10,11,13,22-24}$. Nanobiz ${ }^{\circledR}$ PCR kitinde de 17 kDa'luk lipoproteini kodlayan tul4 geni hedef olarak seçilmiştir.

Yapılan çalışmalarda tul4'e özgül PCR yönteminin saptama sınırı, kan örneklerinde 50 $\mathrm{CFU} / \mathrm{ml}$, fare ve kene doku örneklerinde $<100 \mathrm{CFU} / \mathrm{ml}$, serum örneklerinde ise $10^{3}-10^{4}$ olarak bildirilmiştir ${ }^{18,23,24}$. Ancak çalışmalarda kullanılan PCR yöntemleri (konvansiyonel veya rtPCR) ve analitik duyarlılı̆ın belirlenmesinde kullanılan birimlerin (CFU/ml, kopya/ PCR reaksiyon tüpü, kopya sayısı/ml, DNA konsantrasyonu/ml, genomik ekivalan) farklı oluşu, sonuçların karşılaştıııımasını zorlaştırmaktadır. Bizim çalışmamızda kullanılan PCR kitinin saptama sınırı, reaksiyon başına 100 kopya tul4 geni olarak saptanmışır. Bu değer, F.tularensis tul4 genini hedefleyen önceki konvansiyonel PCR çalışmalarındaki ${ }^{23,24}$ duyarlııı sınırlarına yakın olup, rtPCR yöntemine göre iki kat daha yüksek bulunmuştur. Bu kısmi farklıık, PCR için gerekli tüm reaktiflerin, PCR reaksiyon tüplerinde liyofilize olarak sunulmasının, tüp çeperlerinde absorbsiyona bağlı kısmi kayıplara neden olması şeklinde yorumlanmıştır.

F.tularensis suşları ile standart bakteri DNA'larında Nanobiz ${ }^{\circledR}$ PCR kitinin duyarlılığı, tul4'e özgül "in-house" PCR ve rtPCR ile karşılaştıııldığında \%100 olarak bulunmuştur. Nanobiz ${ }^{\circledR}$ PCR kiti ile Francisella bakterisi ile yakın ilişkili 13 bakteri türünde pozitif sonuç gözlenmemiş (Tablo I) ve özgüllüğün de yüksek (\%100) olduğu belirlenmiş̧ir. Bir kitin güvenilirliğinin değerlendirilmesinde, duyarlılık ve özgüllüğün yanı sıra uygulanabilirlik, kullanım kolaylığı, harcanan zaman ve maliyet gibi kriterler de göz önüne alınmalıdır ${ }^{6}$. F.tularensis'in tanımlanması konvansiyonel PCR ile 7-8 saatte, rtPCR ile 1.5-3 saatte gerçekleşmektedir. Gerçek zamanlı PCR yönteminin konvansiyonel yönteme göre daha basit ve daha kısa iş akışına sahip olması nedeniyle hızlı sonuç vermesine karşın, konvansiyonel PCR'ye göre test ve kurulum maliyetleri daha yüksektir. Diğer yandan çevresel örneklerden DNA izolasyonu için otomatik ekstraksiyon sistemleri uygun olmayıp, örneğin ön işlemlerden geçirilmesi veya ayrı kit kullanılması gereklidir. Bu durum laboratuvar tanısında zaman ve maliyet artıııı bir faktördür.

Tulareminin moleküler tanısında PCR tekniğinin laboratuvarlar arasında standardize edilememiş olması en önemli sorundur 11-13,20. "In-house" yöntemler genellikle iyi performans göstermesine karşın, kullanılan reakiflere, ısı döngü cihazı ve koşullarına, DNA izolasyon yöntemlerine ve işlemi yapan personelin yeterliliğindeki farklılıklara bağlı olarak laboratuvarlar arasındaki uygulamalarda sorunlar yaşanmaktadır ${ }^{11,13}$. Ticari kitler bu sorunların önlenmesi ve tekrarlanabilir sonuçların elde edilmesi için iyi bir alternatif olarak görülmektedir. Ancak, cihaz-ekipman bağımlıı̆̆ı ve reaktiflerin maliyetinin yüksek olması PCR uygulamasının önemli bir dezavantajıdır ${ }^{9,12,13}$. 
Tulareminin kırsal bölge hastalığı olması nedeniyle, laboratuvar altyapısına sahip olmayan yerlerde şüpheli olguların erken tanısı, tedaviye erken başlanması ve komplikasyonların önlenmesi açısından çok önemlidir ${ }^{14-16,20,22}$. Ayrıca, salgınlarda çevresel örneklerin incelenmesi, enfeksiyon kaynaklarının saptanması ve epidemilerin kontrol altına alınmasında oldukça etkilidir ${ }^{1,12,23}$. Ek olarak, biyolojik saldırı durumunda hızlı tanı kapasitesinin sağlanabilmesi için sahada kullanılabilecek, uygulanması kolay, tüm ekipman ve bileşenleri içeren sistemlere intiyaç vardır ${ }^{17-19,21,23}$. Nanobiz ${ }^{\circledR}$ Toolbox sistemi yukarıda belirtilen koşullarda çalışacak şekilde dizayn edilmiş olup, PCR için gerekli tüm bileşenleri içermektedir. Çalışmamızda, bu yöntemin duyarlılık, özgüllük, pozitif ve negatif prediktif değerleri \%100 olarak bulunmuş; uygulaması kolay kullanıma hazır bir sistem olarak, tulareminin endemik olarak görüldüğü kırsal bölgelerdeki fiziki alt yapısı uygun olmayan mikrobiyoloji laboratuvarlarında ve biyoterör olaylarında sahada kullanılma potansiyeli olduğu kanısına varılmıştır.

\section{KAYNAKLAR}

1. World Health Organization. WHO Guidelines on Tularaemia. WHO/CDS/EPR/2007.7. Available at: http:// www.who.int/csr/resources/publications/deliberate/WHO_CDS_EPR_2007_7/en/

2. Kılıç S. Francisella tularensis ve Türkiye'de tularemi epidemiyolojisine genel bir bakış. FLORA 2010; 15(2): 37-58.

3. Kılıç S. Epidemiological characteristics of tularemia in Turkey. International Symposium on Francisella tularensis and Tularemia, 19-23 June 2013, Ürgüp, Nevşehir, Turkey. Symposium Book, p: 15.

4. Ulu Kılıç A, Kılıç S, Şencan i ve ark. İç Anadolu Bölgesinde Francisella tularensis alttür halorctica'ya bağlı su kaynaklı bir tularemi salgını. Mikrobiyol Bul 2011; 45(2): 234-48.

5. Yesilyurt M, Kilic S, Celebi B, et al. Antimicrobial susceptibilities of Francisella tularensis subsp. holarctica strains recovered in Central Anatolia region, Turkey. J Antimicrob Chemother 2011; 66(11): 2588-92.

6. Dikici N, Ural O, Sümer S ve ark. Konya bölgesinde tularemi. Mikrobiyol Bul 2012; 46(2): 225-35.

7. Sjöstedt A. Tularemia: history, epidemiology, pathogen physiology, and clinical manifestations. Ann N Y Acad Sci 2007; 1105: 1-29.

8. Kılıç S. Biyolojik silah olarak bakteriler: kategori A ajanlar. Turk Hij Den Biyol Derg 2006; 63(1-3): 21-46.

9. Wong JD, Shapiro DS. Francisella, pp: 647-51. In: Murray PR, Baron EJ, Pfaller MA, Tenover FC, Volken RH (eds), Manual of Clinical Microbiology. 1999, $7^{\text {th }}$ ed. ASM Press, Washington DC.

10. Tärnvik A, Chu MC. New approaches to diagnosis and therapy of tularemia. Ann N Y Acad Sci 2007; 1105: 378-404.

11. Hepburn MJ, Simpson AJ. Tularemia: current diagnosis and treatment options. Expert Rev Anti Infect Ther 2008; 6(2): 231-40.

12. Johansson A, Forsman M, Sjöstedt A. The development of tools for diagnosis of tularemia and typing of Francisella tularensis. APMIS 2004; 112(11-12): 898-907.

13. Splettstoesser WD, Tomaso H, Al Dahouk S, Neubauer H, Schuff-Werner P. Diagnostic procedures in tularaemia with special focus on molecular and immunological techniques. J Vet Med B Infect Dis Vet Public Health 2005; 52(6): 249-61.

14. Eliasson H, Sjostedt A, Back E. Clinical use of a diagnostic PCR for Francisella tularensis in patients with suspected ulceroglandular tularaemia. Scand J Infect Dis 2005; 37(11-12): 833-7.

15. Sjostedt A, Eriksson U, Berglund L, et al. Detection of F.tularensis in ulcers of patients with tularemia by PCR. J Clin Microbiol 1997; 35(5): 1045-8. 
16. Johansson A, Berglund L, Eriksson U, et al. Comparative analysis of PCR versus culture for diagnosis of ulceroglandular tularemia. J Clin Microbiol 2000; 38(1): 22-6.

17. Lamps LW, Havens JM, Sjostedt A, Page DL, Scott MA. Histologic and molecular diagnosis of tularemia: a potential bioterrorism agent endemic to North America. Mod Pathol 2004; 17(5): 489-95.

18. Tomioka K, Peredelchuk M, Zhu X, et al. A multiplex polymerase chain reaction microarray assay to detect bioterror pathogens in blood. J Mol Diagn 2005; 7(4): 486-94.

19. Matero $\mathrm{P}$, Hemmilä $\mathrm{H}$, Tomaso $\mathrm{H}$, et al. Rapid field detection assays for Bacillus anthracis, Brucella spp., Francisella tularensis and Yersinia pestis. Clin Microbiol Infect 2011; 17(1): 34-43.

20. Versage JL, Severin DD, Chu MC, Petersen JM. Development of a multitarget real-time TaqMan PCR assay for enhanced detection of Francisella tularensis in complex specimens. J Clin Microbiol 2003; 41(12): 5492-9.

21. Fujita O, Tatsumi M, Tanabayashi K, Yamada A. Development of a real-time PCR assay for detection and quantification of Francisella tularensis. Jpn J Infect Dis 2006; 59(1): 46-51.

22. Sjöstedt A, Kuoppa K, Johansson T, Sandström G. The 17 kDa lipoprotein and encoding gene of Francisella tularensis LVS are conserved in strains of Francisella tularensis. Microb Pathog 1992; 13(3): 243-9.

23. Grunow R, Splettstoesser W, McDonald S, et al. Detection of Francisella tularensis in biological specimens using a capture enzyme-linked immunosorbent assay, an immunochromatographic handheld assay, and a PCR. Clin Diagn Lab Immunol 2000; 7(1): 86-90.

24. Higgins JA, Hubalek Z, Halouzka J, et al. Detection of Francisella tularensis in infected mammals and vectors using a probe-based polymerase chain reaction. Am J Trop Med Hyg 2000; 62(2): 310-8. 